\title{
On calculation of the pseudo-inverse econometric models matrix with a rank deficient observation matrix
}

\author{
Viktor Kutovyi ${ }^{1}$, Oleksandr Kutovyi ${ }^{2}$, Oleg Shutovskyi ${ }^{3}$ \\ ${ }^{1}$ Kyiv National Economic University named after Vadym Hetman \\ skutova@ukr.net, orcid.org/0000-0001-6142-1018 \\ 2Bielefeld University (Germany) kutovyi@gmail.com, \\ kutoviy@math.uni-bielefeld.de, orcid.org/0000-0002-2286-5940 \\ ${ }^{3}$ Kyiv National University of Civil Engineering and Architecture \\ shutovsk@ukr.net, orcid.org/0000-0003-2709-2059
}

Received on 20.04.2019, accepted after revision on 20.06.2019 https://doi.org/10.31493/tit1921.0302

\begin{abstract}
The approach to estimating the parameters of linear econometric dependencies for the case of combining a number of special conditions arising in the modeling process is considered. These conditions concern the most important problems that arise in practice when implementing a number of classes of mathematical models, for the construction of which a matrix of explanatory variables is used. In most cases, the vectors that make up the matrix have a close correlation relationship. That leads to the need to perform calculations using a rank deficient matrix. There are also violations of the conditions of the Gauss-Markov theorem. For any non-degenerate square matrix $X$, an inverse matrix $X^{-1}$ is uniquely defined such that, for random right-hand side $B$, the solution of the system $X \beta=B$ is vector $\beta=X^{-1} b$. If $X$ is a degenerate or rectangular matrix, then there is no inverse to it. Moreover, in these cases, the system $X \beta=B$ may be incompatible. Here it is natural to use a generalization of the concept of the inverse transformation, which is formulated in terms of the corresponding problem of minimizing the sum of squared residuals. In the same case, having a QR decomposition, one can use the formula $X^{+}=R^{-1} Q_{1}^{\prime}$. In addition, it is recommended for specific calculations. With an incomplete rank, the most convenient form of representation $X^{-1}$ follows from the expansion in characteristic numbers. If $X=U \sum V$ with non-zero characteristic
\end{abstract}

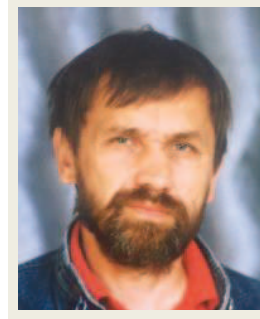

Victor Kutovyi

Department of Economics and Mathematical Modeling PhD, Ass.Prof.

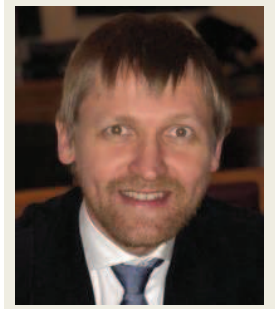

Oleksandr Kutovyi

Department of Mathematik Dr hab, Prof.

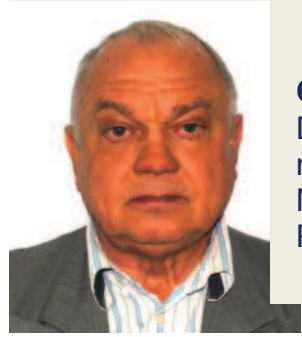

\section{Oleg Shutovskyi}

Department of Information Technologies for Design and Applied Mathematics $\mathrm{PhD}$, Ass.Prof. 


\section{INTRODUCTION}

There are several mathematically equivalent expressions for a matrix pseudo-inverse of $X$. If $X$ is not degenerate, then $X^{+}=X^{\prime}$. When $X$ has a full columnar rank, its pseudoinverse matrix can be represented as $X^{+}=\left(X^{\prime} X\right)^{-1} X^{\prime}$.

In the same case, having a $\mathrm{QR}$ schedule, one can use the formula $X^{+}=R^{-1} Q_{1}^{\prime}$, besides, it is strongly recommended for specific calculations. With incomplete $\operatorname{rank} X$, the most convenient form of representation $X^{-1}$ follows from the schedule by characteristic numbers. If $X=U \sum V$ with $V$ non-zero characteristic numbers, then $X^{+}=V \Sigma^{+} U^{\prime}$. This article proposes an alternative calculation method based on the decomposition of a rank deficient matrix for the product of two full rank matrices.

\section{METHODOLOGY}

Let there be a linear relationship between the variable $Y$ and $\mathrm{m}$ explaining variables $X_{1}, X_{2}, \ldots, X_{\mathrm{m}}$ and the perturbation $\varepsilon, \varepsilon$ is a random variable, emphasizing that only the existence of second-order finite moments is necessary.

If we have a sample of $n$ observations over variables $X_{j}, j=1,2, \ldots m$, then we can write

$$
y_{\mathrm{i}}=\sum_{\mathrm{j}=1}^{\mathrm{m}} x_{\mathrm{ij}} \beta_{\mathrm{j}}+\varepsilon_{\mathrm{i}}, i=1,2, \ldots, n .
$$

Equations (1) can be written in matrix form: $Y=X \beta+\varepsilon$, where (2)

$Y=\left(\begin{array}{c}y_{1} \\ y_{2} \\ \vdots \\ y_{n}\end{array}\right), X=\left(\begin{array}{cccc}x_{11} & x_{12} & \ldots & x_{1 m} \\ x_{21} & x_{22} & \ldots & x_{2 m} \\ \vdots & \vdots & \ddots & \vdots \\ x_{n 1} & x_{n 2} & \ldots & x_{n m}\end{array}\right), \beta=\left(\begin{array}{c}\beta_{1} \\ \beta_{2} \\ \vdots \\ \beta_{m}\end{array}\right), \varepsilon=\left(\begin{array}{c}\varepsilon_{1} \\ \varepsilon_{2} \\ \vdots \\ \varepsilon_{n}\end{array}\right)$

Let's denote through $X^{\prime}$ and $\varepsilon^{\prime}$ the matrices transposed to $X$ and $\varepsilon$, respectively.
Let the following conditions be met:
1) $M \varepsilon=0$
2) $M\left(\varepsilon \varepsilon^{\prime}\right)=\sigma^{2} \cdot E$,

where $E$ is the unit matrix;

3) $X$ is a matrix whose elements are deterministic numbers;

4) rank $X<$ m(matrix $X$-incomplete rank) (6)

In many econometric studies, the assumptions $[10-14]$ of dispersion constancy and the absence of perturbation correlation (4) seem to be unrealistic. Thus, when examining consumer budgets, one can see that the variance of residuals relative to the regression line increases with increasing profits. Similarly, in the analysis of firms activities, the variance of residuals should probably increase with the size of firms.

Therefore, condition (4) should be replaced

$$
M\left(\varepsilon \varepsilon^{\prime}\right)=D=\sigma^{2} W
$$

where $D$ is the covariance $n \times n-\operatorname{matrix}[19]$.

The estimates according parameter $\beta$ least squares in (1) are defined as the $\widehat{\beta}_{1}, \widehat{\beta}_{2}, \ldots \widehat{\beta}_{m}$ minimizing values

$$
\begin{aligned}
& L=\sum_{i=1}^{n} \sum_{k=1}^{n}\left(y_{i}-\sum_{j} x_{i j} \widehat{\beta}_{j}\right) . \\
& \left(y_{k}-\sum_{j} x_{k j} \widehat{\beta}_{j}\right) \alpha_{i k} \rightarrow \min _{(\beta)},
\end{aligned}
$$

where the matrix $A=\left\|\alpha_{i k}\right\|$ is symmetric, decidedly defined $n \times n$ is the matrix. The solution (7) $\widehat{\beta}_{1}, \widehat{\beta}_{2}, \ldots \widehat{\beta}_{m}$ will be called the task pseudo-solution (1-2). The solution will be linear towards $y$. In addition, provided (3) $P_{1} \widehat{\beta}$ will be an unbiased value $P_{1} \beta$ in (1).

That is,

$$
M\left(P_{1} \widehat{\beta}\right)=P_{1} \beta
$$

$P_{1}$ is orthoprojector. 
The solution, generally speaking, will not be the only one. We will try to minimize the amount

$$
\left(\sum_{j=1}^{m} \beta_{j}^{2} \rightarrow \min \right)
$$

Then the solution (7) is unique and is called the normal pseudo-solution of the problem (1$3,4,5,6$ ). When $A \cdot D=E-$ solution (7) is optimal. The Gauss-Markov theorems take place here.

For case (6), unbiased estimates $\beta$ are impossible, but some unbiased linear combinations of unknown parameters can be estimated.

Let be $X$ a non-degenerate matrix, then the solution $(1,2)$ can be written in the form

$$
\widehat{\beta}=X^{-1} Y+X^{-1} \varepsilon,
$$

where $X^{-1}$ - the matrix is inverted to $X$. An inverse matrix is a very useful mathematical concept and often needs to be calculated $X^{-1}$. In the case of a problem (MLS), the question arises whether there is a $m \times n$ matrix $Z$, which uniquely defined by the matrix $X$ and it is such that a solution for single minimum length $\left(\sum \beta_{i}^{2} \rightarrow \min \right)$ (MLS) is expressed by the formula $\widehat{\beta}=Z Y$.

Such a matrix $Z$ does exist [20], it is called a pseudo-inverse of the matrix $X$ and is denoted $X^{+}$. For the sake of simplicity, we put it $W=E$.

The matrix $X^{+}$is uniquely determined by the matrix $X$ and does not depend on the specific orthogonal decomposition $X$ [20]. For each $j, 1 \leq j \leq n \quad j$ is the column of the ma$\operatorname{trix} X_{j}$ can be written in the form $X_{j}=X^{+} e_{j}$ where $e_{j} j$ - the column of a single matrix $E$

So $\widehat{\beta}=X^{+} Y$. The purpose of the article is to constructively define and calculate $X^{+}$.

\section{Definition 1.}

For random $n \times m$ matrix $X$, the pseudoinverse matrix, denoted $X^{+}$, is the $m \times n$ ma- trix $j$ - the column of which is the only minimum length (MLS) solution. $X \widehat{\beta}=e_{j}$.

\section{Definition 2.}

Matrix $X^{+}$of a $m \times n$ size is called a Moore-Penrose pseudo-inverse matrix for ma$\operatorname{trix} X$, if it satisfies the following four conditions

1) $X^{+} X X^{+}=X^{+}$

2) $X X^{+} X=X$

3) $\left(X^{+} X\right)^{\prime}=X^{+} X$ - symmetrical

4) $\left(X X^{+}\right)^{\prime}=X X^{+}-$symmetrical.

From the condition $X^{+} X X^{+}=X^{+}$it follows $X^{+} X X^{+} X=X^{+} X$.

Denote $X^{+} X=P_{1}$, then $P_{1}^{2}=P_{1}$, that is $P_{1}$ - idempotent.

Similarly $X X^{+}=P_{2}$.

From conditions $(3,4)$ we obtain $P_{1}, P_{2}$ orthoprojectors [21]. It can be proved that the general solution of problem (1) is expressed by the formula

$$
\widehat{\beta}=X^{+} Y+\left(E-P_{1}\right) \bar{C},
$$

where $\bar{C}$ is a random vector.

One can prove that a matrix defined $X^{+}$always exists and is a unique one. If $X$ is a nondegenerate square matrix, then $X^{+}=X^{-1}$ obviously satisfies the conditions $(1-4)$.

\section{Theorem 1.}

If the $X-n \times m$ matrix $n>m$ and $\operatorname{rank} X=m$, that is, has a full rank, then $X^{+}=\left(X^{\prime} X\right)^{-1} X^{\prime}$. If the $X-n \times m$ matrix $m>n$, then $X^{+}=X^{\prime}\left(X X^{\prime}\right)^{-1}$.

\section{Proof.}

Let $X$ be a full rank matrix. $z=\left(X^{\prime} X\right)^{-1} X^{\prime}$. Let's check the Moore-Penrose conditions. Let it $n>m$. 


\section{Proof.}

Let $X$ be a full rank matrix. $z=\left(X^{\prime} X\right)^{-1} X^{\prime}$.

Let's check the Moore-Penrose conditions. Let it $n>m$.

1) $Z X Z=\left(X^{\prime} X\right)^{-1} X^{\prime} X\left(X^{\prime} X\right)^{-1} X^{\prime}=$ $=\left(X^{\prime} X\right)^{-1} X^{\prime}=Z$

2) $X Z X=X\left(X^{\prime} X\right)^{-1} X^{\prime} X=X$

3) $Z X=\left(X^{\prime} X\right)^{-1} X^{\prime} X=P_{1}$ - orthoprojektor $\Rightarrow$ $\Rightarrow P_{1}$ - symmetrical [21]

4) $X Z=X\left(X^{\prime} X\right)^{-1} X^{\prime}$ - symmetrical .

Let it $m>n, Z=X^{\prime}\left(X X^{\prime}\right)^{-1}$

1) $Z X Z=X^{\prime}\left(X X^{\prime}\right)^{-1} X X^{\prime}\left(X X^{\prime}\right)^{-1}=X^{\prime}\left(X X^{\prime}\right)^{-1}=Z$

2) $X Z X=X X^{\prime}\left(X X^{\prime}\right)^{-1} X=X$

3) $X Z=X X^{\prime}\left(X X^{\prime}\right)^{-1}=P_{2}-$ orthoprojektor $\Rightarrow$ $P_{2}$ - symmetrical [21]

4) $Z X=X^{\prime}\left(X X^{\prime}\right)^{-1} X$-symmetrical .

Moore-Penrose conditions are necessary and sufficient for the matrix $Z$ to be equal $X^{+}$ [2].

The theorem is proved.

\section{Lemma 1.}

Let it be the $X-n \times m$ matrix $\operatorname{rang} \mathrm{X}=\mathrm{r} \quad(r<m<n)$.

Then $X=A B, A-n \times r-$ is a full rank matrix, $-B-r \times m$ is a full rank matrix.

\section{Proof.}

Let it $X=\left\{X_{1}, X_{2}, \ldots, X_{m}\right\}, X_{j}$ is a column $X(j=\overline{1, m})$. Let $A=\left\{X_{1}, X_{2}, \ldots, X_{r}\right\}$, where $X_{1}, X_{2}, \ldots, X_{r}$ are the basic columns. Then any $X_{j}$ is a linear combination of basis columns

$$
\begin{aligned}
& X_{j}=\sum_{k=1}^{r} b_{k j} X_{k} \Rightarrow x_{i j}=\sum_{k=1}^{r} x_{i k} b_{k j} . \text { so } \\
& (X=A B) \text {. } \\
& A=\left\|x_{i k}\right\|_{k=\overline{(1, n)}}^{i=\overline{(1, r)}} ; \quad B=\left\|b_{k j}\right\|_{\substack{j=\overline{(1, m)} \\
k=(1, r)}} ;\left\|x_{i j}\right\|_{\substack{i=\overline{(1, n)} \\
j=\overline{(1, m)}}}
\end{aligned}
$$

$A$ contains $r$ base columns, therefore $\operatorname{rang} \mathrm{A}=\mathrm{r} . \quad B$ contains all columns of a single matrix $E$. So $\operatorname{rang} B=r$. Lemma proved. $X=A B$ and by theorem $1 A^{+}=\left(A^{\prime} A\right)^{-1} A^{\prime}$, $B^{+}=B^{\prime}\left(B B^{\prime}\right)^{-1}$.

\section{Theorem 2.}

$$
X^{+}=B^{\prime}\left(B B^{\prime}\right)^{-1}\left(A^{\prime} A\right)^{-1} A^{\prime}
$$

\section{Proof.}

It is known that $(A B)^{-1}=B^{-1} A^{-1}$. Pseudoinverse equality $(A B)^{+}=B^{+} A^{+}$is not always fulfilled.

Let us prove that

$$
X^{+}=(A B)^{+}=B^{+} A^{+}=B^{\prime}\left(B B^{\prime}\right)^{-1}\left(A^{\prime} A\right)^{-1} A^{\prime} .
$$

Let's check Moore-Penrose's conditions for

$Z=B^{\prime}\left(B B^{\prime}\right)^{-1}\left(A^{\prime} A\right)^{-1} A^{\prime}$

1) $A B Z A B=A B B^{\prime}\left(B B^{\prime}\right)^{-1}\left(A^{\prime} A\right) A^{\prime} A B=A B$

2) $Z A B Z=$

$=B^{\prime}\left(B B^{\prime}\right)^{-1}\left(A^{\prime} A\right)^{-1} A^{\prime} A B B^{\prime}\left(B B^{\prime}\right)^{-1}\left(A^{\prime} A\right)^{-1} A^{\prime}=$ $=B^{\prime}\left(B B^{\prime}\right)^{-1}\left(A^{\prime} A\right)^{-1} A^{\prime}=Z$

3) $Z A B=B^{\prime}\left(B B^{\prime}\right)^{-1}\left(A^{\prime} A\right)^{-1} A^{\prime} A B=$

$=B^{\prime}\left(B B^{\prime}\right)^{-1} B=P_{1}$-symmetrical

4) $A B Z=A B B^{\prime}\left(B B^{\prime}\right)^{-1}\left(A^{\prime} A\right)^{-1} A^{\prime}=$

$=A\left(A^{\prime} A\right)^{-1} A^{\prime}=P_{2}$ - symmetrical .

So Moore's conditions are fulfilled, and therefore $Z=(A B)^{+}=B^{+} A^{+}=X^{+}$. The theorem is proved.

The solution $(1,2) \widehat{\beta}$ is determined simultaneously: $\widehat{\beta}=X^{+} Y+\left(E-P_{1}\right) C$. Vector $\mathrm{C}$ is random.

Therefore, if the matrix $\mathrm{X}$ is incomplete, then it is impossible to find an unbiased value $\widehat{\beta}$. Consider $\widehat{\beta}$ the normal solution to problem $(1,2)$. Indeed, 


$$
\begin{aligned}
& \widehat{\beta}=X^{+} Y=(A B)^{+} Y= \\
& =B^{\prime}\left(B B^{\prime}\right)^{-1}\left(A^{\prime} A\right)^{-1} A^{\prime}(A B \beta+\varepsilon)= \\
& =B^{\prime}\left(B B^{\prime}\right)^{-1}\left(A^{\prime} A\right)^{-1} A^{\prime} A B \beta+ \\
& +B^{\prime}\left(B B^{\prime}\right)^{-1}\left(A^{\prime} A\right)^{-1} A^{\prime} \varepsilon= \\
& =B^{\prime}\left(B B^{\prime}\right)^{-1} B \beta+B^{\prime}\left(B B^{\prime}\right)^{-1}\left(A^{\prime} A\right)^{-1} A^{\prime} \varepsilon= \\
& =P_{1} \beta+X^{+} \varepsilon, \quad M \widehat{\beta}=P_{1} \beta \neq \beta .
\end{aligned}
$$

\section{Definition 2.}

The $\hat{\beta}$ parameter value is called $X-$ unbiased if $M X \widehat{\beta}=X \beta$.

\section{Lemma 2.}

The value $\widehat{\beta}=X^{+} Y$ is an unbiased value $\beta$

\section{Proof.}

We use (2), then

$\widehat{\beta}=X^{+} Y=X^{+}(X \beta+\varepsilon)=X^{+} X \beta+X^{+} \varepsilon$,

hence from (3) and (9)

$$
\begin{aligned}
& M(X \widehat{\beta})=M\left(X X^{+} X \beta+X X^{+} \varepsilon\right)= \\
& X X^{+} X \beta=X \beta
\end{aligned}
$$

Otherwise

$$
\begin{aligned}
& \widehat{\beta}=B^{\prime}\left(B B^{\prime}\right)^{-1}\left(A^{\prime} A\right)^{-1} A^{\prime}(A B \beta+\varepsilon) \\
& X \widehat{\beta}=A B \widehat{\beta}=A B B^{\prime}\left(B B^{\prime}\right)^{-1}\left(A^{\prime} A\right)^{-1} A^{\prime} A B \beta+ \\
& A B B^{\prime}\left(B B^{\prime}\right)^{-1}\left(A^{\prime} A\right)^{-1} A^{\prime} \varepsilon= \\
& =A B \beta+A\left(A^{\prime} A\right)^{-1} A^{\prime} \varepsilon=X \beta+A\left(A^{\prime} A\right)^{-1} A^{\prime} \varepsilon . \\
& M X \widehat{\beta}=X \beta .
\end{aligned}
$$

\section{Lemma is proved.}

$$
M \widehat{\beta}=B^{\prime}\left(B B^{\prime}\right)^{-1} B \beta=P_{1} \beta .
$$

So, in general, $\widehat{\beta}$ is a biased value of $\beta$.

Let us estimate the variation $\widehat{\beta}-$ disperse $\widehat{\beta}$ towards with $M \widehat{\beta}$ :

$$
\begin{aligned}
& \operatorname{var} \widehat{\beta}= \\
& =M B^{\prime}\left(B B^{\prime}\right)^{-1}\left(A^{\prime} A\right)^{-1} A^{\prime} \varepsilon \varepsilon^{\prime} A\left(A^{\prime} A\right)^{-1}\left(B B^{\prime}\right)^{-1} B= \\
& =\sigma^{2} B^{\prime}\left(B B^{\prime}\right)^{-1}\left(A^{\prime} A\right)^{-1}\left(A^{\prime} A\right)\left(A^{\prime} A\right)^{-1}\left(B B^{\prime}\right) B= \\
& =\sigma^{2} B^{\prime}\left(B B^{\prime}\right)^{-1}\left(A^{\prime} A\right)^{-1}\left(B B^{\prime}\right)^{-1} B= \\
& =\sigma^{2} B^{\prime}\left(B B^{\prime} A^{\prime} A B B^{\prime}\right)^{-1} B= \\
& =\sigma^{2} B^{\prime}\left(B(A B)^{\prime} A B B^{\prime}\right)^{-1} B= \\
& =\sigma^{2} B^{\prime}\left(B X^{\prime} X B^{\prime}\right)^{-1} B
\end{aligned}
$$

\section{Consequence 1.}

$$
\begin{aligned}
& M\left(B^{\prime}\left(B B^{\prime}\right)^{-1} B \widehat{\beta}\right)=B^{\prime}\left(B B^{\prime}\right)^{-1} B M(\widehat{\beta})= \\
& =P_{1} M \widehat{\beta}=P_{1}^{2} \beta=P_{1} \beta,
\end{aligned}
$$

$\widehat{\beta}$ is $P_{1}-$ an unbiased value $\beta$.

In general $\widehat{\beta}$ is defined ambiguously

$$
\widehat{\beta}=X^{+} Y+\left(E-P_{1}\right) C .
$$

\section{Theorem 3.}

The covariance matrix $D(X \widehat{\beta})$ of the $X \widehat{\beta}$ parameter estimates $X \beta$ in model (2) is equal[20]

$$
D(X \widehat{\beta})=\sigma^{2} X\left(X^{\prime} X\right)^{+} X^{\prime},
$$

where $\left(X^{\prime} X\right)^{+}$- pseudo-inverse to $\left(X^{\prime} X\right)$.

\section{Proof.}

We use lemma (2):

$$
X^{+}=\left(X^{\prime} X\right)^{+} X^{\prime}, X^{+} Y=X^{+} X \beta+X^{+} \varepsilon .
$$

Then

$$
X \widehat{\beta}=X X^{+} Y=X X^{+} X \beta+X X^{+} \varepsilon==X \beta+X X^{+} \varepsilon .
$$

So using (3), (4), (9) we obtain

$$
\begin{aligned}
& D(X \widehat{\beta})=M(X \widehat{\beta}-X \beta)(X \widehat{\beta}-X \beta)^{\prime}= \\
& M\left(X X^{+} \varepsilon, \varepsilon^{\prime}\left(X X^{+}\right)^{\prime}\right)=
\end{aligned}
$$




$$
\begin{aligned}
& =M\left(X\left(X^{\prime} X\right)^{+} X^{\prime} \varepsilon \varepsilon^{\prime} X\left(X^{\prime} X\right)^{+} X^{\prime}\right)= \\
& =\sigma^{2} X\left(X^{\prime} X\right)^{+}\left(X^{\prime} X\right)\left(X^{\prime} X\right)^{+} X^{\prime}= \\
& \sigma^{2} X\left(X^{\prime} X\right)^{+} X^{\prime}
\end{aligned}
$$

\section{Otherwise}

$$
\begin{aligned}
& D(X \widehat{\beta})=M(X \widehat{\beta}-X \beta)(X \widehat{\beta}-X \beta)^{\prime}= \\
& =M\left(A B B^{\prime}\left(B B^{\prime}\right)^{-1}\left(A^{\prime} A\right)^{-1} A^{\prime} \varepsilon \varepsilon^{\prime} A\left(A^{\prime} A\right)^{-1} .\right. \\
& \left(B B^{\prime}\right)^{-1} B B^{\prime} A=\sigma^{2} A\left(A^{\prime} A\right)^{-1} A^{\prime}=\sigma^{2} P_{2} .
\end{aligned}
$$

The theorem is proved.

\section{Consequence 2.}

$D(X \widehat{\beta})$ does not depend on non-basic vector-columns of the matrix $X$.

Suppose that $c=\left(\begin{array}{c}c_{1} \\ c_{2} \\ \vdots \\ c_{m}\end{array}\right)^{\prime}$ belongs to the linear shell of the rows $x_{1}, x_{2}, \cdots, x_{n}$ of the matrix $X$.

Then $c=\gamma X$ where

$$
\gamma=\left\{\gamma_{1}, \gamma_{2}, \cdots, \gamma_{n}\right\}
$$

Then according to (11)

$$
\gamma X \widehat{\beta}-M(\gamma X \widehat{\beta})=\gamma X X^{+} \varepsilon .
$$

Besides, $c=\gamma X, M(c \widehat{\beta})=c \beta$.

Therefore, we get

$$
\begin{aligned}
& D(c \widehat{\beta})=M(c \widehat{\beta}-c \beta)(c \widehat{\beta}-c \beta)^{\prime}= \\
& M(\gamma X \widehat{\beta}-\gamma X \beta)(\gamma X \widehat{\beta}-\gamma X \beta)^{\prime}= \\
& =M\left(\gamma X X^{+} \varepsilon \varepsilon^{\prime} X^{+\prime} X^{\prime} \gamma^{\prime}\right)= \\
& M\left(\gamma X\left(X^{\prime} X\right)^{+} X^{\prime} \varepsilon \varepsilon^{\prime} X\left(X^{\prime} X\right)^{+} X^{\prime} \gamma^{\prime}\right)= \\
& =\sigma^{2} \gamma X\left(X^{\prime} X\right)^{+} X^{\prime} X\left(X^{\prime} X\right)^{+} X^{\prime} \gamma^{\prime}= \\
& \sigma^{2} \gamma X\left(X^{\prime} X\right)^{+} X^{\prime} \gamma^{\prime}=c\left(X^{\prime} X\right)^{+} c^{\prime} .
\end{aligned}
$$

\section{CONCLUSIONS}

Thus, if the matrix of an accurate system is incomplete, then minor values of the perturba- tions of the input data and rounding errors will not necessarily lead to the appearance in the process of transformation of the system any rows or columns consisting entirely of the same small elements. This is the main, but not the only, difficulty in constructing numerical methods for decomposing systems with rank deficient matrices, which is built on equivalent transformations of the original system.

Another difficulty is connected with the reasoning for further transformations of those systems whose matrices have rows and columns with minor elements.

If the input data of a system with a rank deficient matrix is given with errors, no increase in the accuracy of the calculations and no transformations will provide the guaranteed accuracy of a normal pseudo-solution. This requires additional information about the exact task involved. But suppose that after the unitary transformations, a system with small rows or columns is obtained. Replacing these rows and columns with zero values is equivalent to a small perturbation of the initial system matrix. If we can accurately find the normal pseudo-solution of the resulting system, it will mean that the projection of the normal pseudosolution of the exact system on one of the subspaces drawn on singular vectors will be calculated sufficiently accurately. There is no reason to expect a better result without additional information.

\section{REFERENCES}

1. Johnston J., 1971. Econometric Methods. MeGraw-Hill, 437.

2. Lawson C.L., Hanson R.J., 1974. Solving Least Squares Problems. Prentice-Hall, Inc., Englewood Cliffs N.J., 340.

3. Voevodin V.V., 1977. Vychislitel'nye osnovy lineinoi algebry [numerical foundations of linear algebra]. Moscow, Nauka, 303 (in Russian).

4. Kutovyi V.O., 2001. Pro teoremu HaussaMarkova u vypadku vyrodzhenoi matrytsi sposterezhen. Dopov. Dokl. Akad. Nauk Ukraine, No.5, 19-22 (in Ukrainian).

5. Kutovyi V.O., 2000. Pro zastosuvania instrumentalnyh zminnyh dlia vyznachenia parametriv zagalnoi liniynoi modeli Modeliuvayia ta informaciyni systey v economici. Kyiv.KNEU, No.64, 168-173 (in Ukrainian). 
6. Kutovyi V.O., Roskach O.S., 1997. Matematyko-statystychne uzagalnenia pokrokovyh metodiv pobudovy predyktornyh prostoriv. Mashynna obrobka informacii, No.59, 140-149 (in Ukrainian).

7. Kutovyi V.O., Roskach O.S., 1997. Pro zastosyvania na EOM algorytmu FarraraGlaubera.Mashyna obrobka informacii. Kyiv, KNEU, No.61, 142-149 (in Ukrainian).

8. Kutovyi V.O., 1999. Pro umovy zastosuvania teoremy Gaussa-Markova. Vcheni zapysky Kyiv, KNEU, No.2C, 206-208 (in Ukrainian).

9. Kutovyi V.O., 2001. Pro efektyvnist zmishenyh ocinok parametriv economichnyh modelei. Kyiv, KNEU, No.3, 324-326 (in Ukrainian).

10.Aitken A.C., 1993. One Least-squares and Linear Combination of Observations. Proc., Royal Soc., Edinburgh, No.55, 42-46.

11.Pavies O., 1993. Statistical moments in research and production, New York, 1957.

12.Plackett R., 1960. Principles of regression analysis. Oxford.

13.Weatherburn C.E., 1961. A first course in mathematical statistics. University Press, Cambridge, brosch, 18s, 6d, 278 .

14.Hamilton W., 1964. Statistics in physical science. New York, 1964.

15.Jürgen Grob., 2004. The general Gauss-Markov model with possible singular dispersion matrix. Statistical Paper, No.45, 311-336.

16.Farrar D.E., Glauber R.R., 1967. Multicollinearity in Regression Analysis: The Problem Revisited. Review of Economics and Statistics, 49(1), 92-107.

17.Yangge Fian, Beisiegel M., Dagenais E., Haines C., 2008. On the natural restrictions in the singular Grauss-Markov model. Statistical Papers, Vol.49, 553-564.

18.Silvey S.D., 1969. Multicallinearity and Imprecise Estimation. Journal of the Real Statical Society, Series B, No.31, 539-552.

19.Kutovyi V.O., Katunina O.S., 2017. Projecting predicators for econometric models with matrix of supervisory range obstructions. Моделювання та інформаційні системи в економіці, КНЕУ, No.94, 178-194.

20.Viktor Kutovyi, Olga Katunina, Oleg Shutovskyi, 2018. Analysis of the multicollinear econometric model parameters with a rank deficient observation matrix. Transfer of Innovative Technologies, Vol.1(1), 75-88.

21.Ахиезер Н.И., Глазман И.И. Теория линейных операторов в Гильбертовом пространстве. Москва, Наука, 543.

\section{О вычислении псевдообратной матрицы \\ эконометрических моделей с матрицей наблюдений неполного ранга}

\section{Виктор Кутовой, Александр Кутовой, Олег Шутовский}

Аннотация. Рассмотрен подход оценивания параметров линейных эконометрических зависимостей для случая сочетания ряда особых условий, возникающих в процессе моделирования. Эти условия касаются наиболее важных проблем, возникающих на практике при реализации ряда классов математических моделей, для построения которых используется матрица объясняющих переменных. В большинстве случаев векторы, из которых составляется матрица, имеют тесную корреляционную связь. Что приводит к необходимости выполнять вычисления с использованием матрицы неполного ранга. Также имеют место нарушения условия теоремы Гаусса-Маркова. Для любой невырожденной квадратной матрицы $X$ однозначно определена обратная матрица $X^{-1}$ такая, что при произвольной правой части $B$ решением системы $X \beta=B$ будет вектор $\beta=X^{-1} b$. Если $X$ - вырожденная или прямоугольная матрица, то обратной к ней не существует. Более того, в этих случаях система $X \beta=B$ может оказаться несовместимой. Здесь естественно пользоваться обобщением понятия обратного преобразования, которое формулируется в терминах соответствующей задачи минимизации суммы квадратов невязок. В этом же случае, имея QRразложение, можно использовать формулу $X^{+}=R^{-1} Q_{1}^{\prime}$. Кроме того, именно она рекомендуется для конкретных вычислений. При неполном ранге наиболее удобная форма представления $X^{-1}$ вытекает из разложения по характеристическим числам. Если $X=U \sum V$ с $V$ ненулевыми характеристичными числами, то $X^{+}=V \sum^{+} U^{\prime}$. Нами предлагается альтернативный способ вычисления $X^{+}$, который опирается на разложении матрицы $X$ неполного ранга на произведение двух матриц полного ранга.

Ключевые слова: эконометрическая модель, матрица неполного ранга, условия Гаусса-Маркова, псевдообратная матрица. 